\title{
Efficacy of the combination use of aprepitant and palonosetron for improving nausea in various moderately emetogenic chemotherapy regimens
}

Naohisa Yoshida ${ }^{1,2^{*}}$ (D), Tetsuya Taguchi ${ }^{2,3}$, Masayoshi Nakanishi ${ }^{4}$, Ken Inoue $^{1}$, Tetsuya Okayama', Takeshi Ishikawa ${ }^{1,2}$, Eigo Otsuji ${ }^{4}$, Koichi Takayama ${ }^{2,5}$, Haruo Kuroboshi ${ }^{2,6}$, Motohiro Kanazawa ${ }^{7}$ and Yoshito Itoh ${ }^{1}$

\begin{abstract}
Background: Nausea is more difficult to control than vomiting in chemotherapy. We therefore analyzed the efficacy of a strong supportive treatment with aprepitant, palonosetron, and dexamethasone against nausea for various moderately emetogenic chemotherapy (MEC).

Methods: A total of 312 cases treated by palonosetron with or without aprepitant receiving MEC regimens using oxaliplatin, carboplatin, and irinotecan from 2014 to 2016 in our outpatient center for digestive organ cancers, lung cancers, and gynecological cancers were analyzed. Through propensity score matching analysis, cases were divided into 97 cases receiving 2 drugs (palonosetron+dexamethasone) and 97 receiving 3 drugs (aprepitant+palonosetron+dexamethasone). We examined the control rates of nausea for the first two consecutive courses in the both groups. Additionally, risk factors for acute and delayed nausea were analyzed using a multivariate analysis among overall 312 cases.
\end{abstract}

Results: The control rates of nausea in the two- and the three-drug groups were as follows: acute, 92.8 and 95.9\% ( $p=0.35)$; and delayed, 83.5 and $81.4 \%(p=0.85)$, although the control rates of vomiting exceeded $95 \%$ in both groups. A multivariate analysis showed that significant risk factors for acute nausea (odds ratio, 95\% confidence interval) were elevation of serum creatinine (12.601, 2.437-65.157), general fatigue (3.728, 1.098-12. 661), and performance status (PS) 2 (19.829, 3.200-122.865). The significant risk factors for delayed nausea were elevation of alanine aminotransferase (2.397, 1.153-4.984), general fatigue (2.652, 1.380-5.097), and PS 2 $(5.748,1.392-23.740)$.

Conclusions: The control for nausea in MEC was insufficient even with palonosetron and aprepitant, and we should pay attention to risk factors for preventing nausea.

Keywords: Palonosetron, Aprepitant, MEC, Nausea, Chemotherapy

\footnotetext{
* Correspondence: naohisa@koto.kpu-m.ac.jp

'Department of Molecular Gastroenterology and Hepatology, Graduate School of Medical Science, Kyoto Prefectural University of Medicine, 465 Kajii-cho, Kawaramachi-Hirokoji, Kamigyo-ku, Kyoto 602-8566, Japan

${ }^{2}$ Outpatient Cancer Chemotherapy Center, Kyoto Prefectural University of Medicine Hospital, Kyoto, Japan

Full list of author information is available at the end of the article
}

(c) The Author(s). 2019 Open Access This article is distributed under the terms of the Creative Commons Attribution 4.0 International License (http://creativecommons.org/licenses/by/4.0/), which permits unrestricted use, distribution, and reproduction in any medium, provided you give appropriate credit to the original author(s) and the source, provide a link to the Creative Commons license, and indicate if changes were made. The Creative Commons Public Domain Dedication waiver (http://creativecommons.org/publicdomain/zero/1.0/) applies to the data made available in this article, unless otherwise stated. 


\section{Background}

Chemotherapy-induced nausea and vomiting (CINV) is a major side effect that can reduce the oral intake and adversely affect the patient's quality of life [1]. Nausea in particular is reported to have a stronger negative impact on patients' daily lives than vomiting [2]. Indeed, a study showed that the food intake decreased by $300-500 \mathrm{kcal} /$ day even in patients with mild nausea compared to patients with no nausea [3]. Therefore, it is very important to prevent all degrees of nausea in order to maintain a good patient status during chemotherapy.

Recent guidelines for antiemetic treatments, such as the National Comprehensive Cancer Network (NCCN), Multinational Association of Supportive Care in Cancer (MASCC), the American Society of Clinical Oncology (ASCO), and the Japanese guidelines, describe the classifications of emetogenic risks for each anticancer drug and regimen [4-7], resulting in categories of high emetogenic chemotherapy (HEC), moderate emetogenic chemotherapy (MEC), low emetogenic, and minimal emetogenic chemotherapy. Among MEC regimens, two-drug treatments, such as the first-generation 5-hydroxytryptamine-3 receptor antagonist (5 HT3RA) and dexamethasone (DEX), are regularly recommended, and additional aprepitant is needed for some drugs, such as carboplatin (CBDCA) and irinotecan (CPT-11). Aprepitant is a neurokinin 1 receptor antagonist (NK1RA), and its effectiveness against delayed CINV has been reported in many studies on HEC and MEC regimens [8, 9]. However, a study of an oxaliplatin (L-OHP)-based regimen for colorectal cancer showed that the control rate of acute and delayed nausea (mild to severe) by 3-drugs therapy (NK1RA+ 5HT3RA + DEX) was 93.6 and 66.3\%, respectively, compared to 2-drugs therapy (5HT3RA + DEX) (acute: 90.2\%, $p=0.23$, delayed: 61.8\%, $p=0.36$ ) though first-generation 5HT3RA was used in almost half of cases [9].

Palonosetron is a second-generation 5HT3RA with a longer half-life than the first-generation 5HT3RA [10]. According to several guidelines, three-drug treatment including palonosetron is recommended for preventing CINV due to HEC [4-7]. On the other hand, the ASCO and MASCC guidelines recommend that palonosetron should be used for MEC regimens when NK1RA is not used $[5,6]$. A review of palonosetron showed the control rates for acute and delayed nausea in palonosetron+DEX in various MEC regimens to be $70-80 \%$ and $60-\% 70 \%$, respectively, which were better than those of the firstgeneration 5HT3RA was still low [10]. Thus, nausea is not sufficiently prevented according to the recommendations of the recent guidelines.

In this study, we hypothesized that the strongest threedrug treatment (NK1RA + panlonosetron+DEX) may show better control for delayed nausea for MEC regimens than regular recommended treatments and analyzed the efficacies of strong three-drug treatments for nausea associated with various $\mathrm{MEC}$ regimens.

\section{Methods}

This was an observational study. Among 16,659 patients having various cancers from May 2014 to May 2016 in our outpatient cancer chemotherapy center, 563 cases receiving $\mathrm{MEC}$ was analyzed. To analyze MEC regimens using L-OHP, CDBCA, and CPT-11, 134 patients with breast cancer and patients with 50 pancreatic cancer were excluded. Then, the cumulative 312 cases treated by palonosetron in MEC with or without NK1RA using L-OHP, CBDCA, and CPT-11 for digestive organ cancers (colorectal cancer and gastric cancer), lung cancers, and gynecological cancers (ovarian cancer, cervical cancer, endometrial cancer) were analyzed (Fig. 1).

According to anti-emetic therapies, the 312 cases were divided into 97 cases receiving 2 drugs (palonosetron and DEX) and 215 cases receiving 3 drugs (NK1RA, palonosetron, and DEX). Then, we performed a propensity score matching to control and to reduce selection bias in each group. Matching covariates were as follows: age, sex, Eastern Cooperative Oncology Group (ECOG) scale performance status (PS) scale, primary organ, and type of anticancer drug. Finally, 97 cases in the two-drug group and 97 cases in the three-drug group were analyzed (Fig. 1). The first-course chemotherapy and its associated CINV were analyzed in all patients. However, some patients received first-course chemotherapy at admission; for those cases, the second-course chemotherapy and its associated CINV were analyzed. In patients receiving multiple courses of $\mathrm{MEC}$, the data for two consecutive courses of chemotherapy in our outpatient center were analyzed. Additionally, which 5HT3RA such as first-generation or palonosetron were administered in both the two- and three-drug groups, were decided by each doctor according to patient characteristics including those who received CINV as a previous chemotherapy. In addition, whether or not NK1RA was used was also decided by each doctor. The exclusion criteria were as follows: patients with severe organ disorders; patients having complications that induced nausea and/or emesis (e.g. brain metastases and ulcerative diseases); and the administration of drugs that cause nausea and/or emesis during the investigation period, except for antiemetics (e.g. major or minor tranquilizers, or corticosteroids for any other reason).

In both the two- and three-drug groups, various clinical characteristics, including the age, sex, ECOG PS scale, primary organ, type of anticancer drug, sequence of chemotherapy (first course or not-first course), and additional oral DEX day 2-3 days of chemotherapy were analyzed [11]. The control rates of nausea and vomiting 


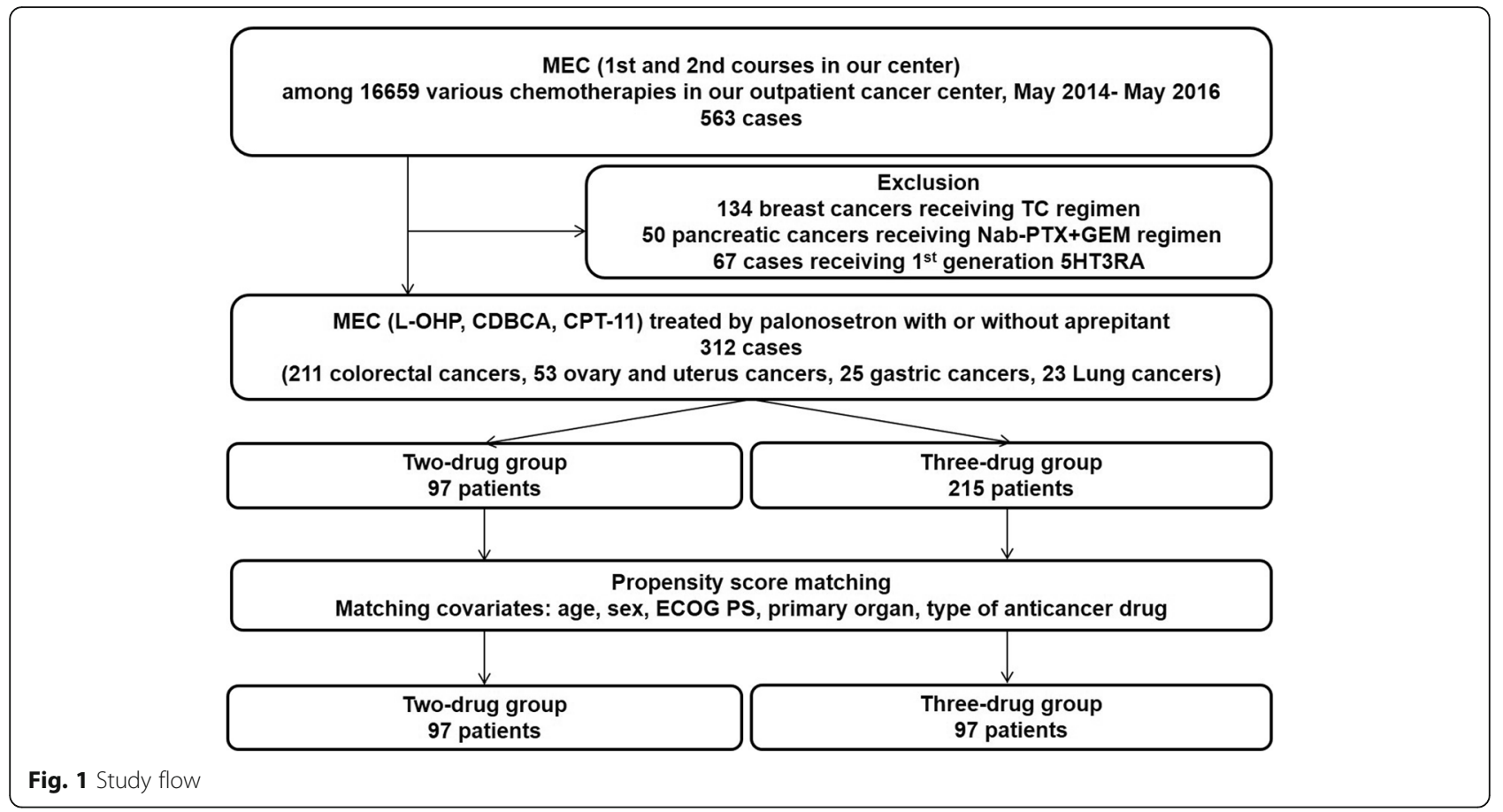

were analyzed in both groups along with the rates for acute phase $(<24 \mathrm{~h})$ and delayed phase $(\geq 24 \mathrm{~h})$. Additionally, the control rates for nausea and vomiting for each anticancer drug (L-OHP, CBDCA, CPT-11, and oral 5-fluorouracil (5-FU)) were also examined in both groups. Furthermore, all 312 cases before propensity score matching were divided into cases with or without nausea and various clinical factors, such as patient characteristics (age, sex, PS) and symptoms (pain, constipation, diarrhea, oral mucositis, neuropathy, general fatigue) and blood examination findings (neutrophil value $[\mathrm{NEUT}]$, hemoglobin $[\mathrm{Hb}]$, platelet $[\mathrm{PLT}]$, creatinine [CRE], alanine aminotransferase [AST], aspartate aminotransferase [ALT]). A multivariate analysis was performed to clarify the risk factors of acute and delayed nausea in all 312 cases receiving palonosetron.

In this study, all symptoms including nausea and vomiting were recorded using a questionnaire, which was used in our center since 2012 for all patients. The questionnaire was written by each patient in our center with a help of our qualified nurses who didn't know this study. The questionnaire was made according to the $\mathrm{Na}$ tional Cancer Institute - Common Toxicity Criteria (NCI-CTC) grade ver. 4.0 after every course of chemotherapy [12]. Regarding pain, it was scored using a numerical rating score (NRS: $0-10$ ).

This study was approved by the ethics committee of Kyoto Prefectural University of Medicine and was carried out in accordance with the World Medical Association Helsinki Declaration (adopted in 1964 and amended in 1975, 1983, 1989, 1996, 2000, 2002, 2004, and 2008).

\section{Chemotherapy regimens}

Regarding colorectal cancer, patients on mFOLFOX6 received concurrent L-OHP $\left(85 \mathrm{mg} / \mathrm{m}^{2}\right)$ and leucovorin (LV) $\left(400 \mathrm{mg} / \mathrm{m}^{2}\right)$ for $2 \mathrm{~h}$ on day 1 followed by bolus 5 -FU $\left(400 \mathrm{mg} / \mathrm{m}^{2}\right)$ and subsequent continuous infusion of 5 -FU $\left(2400 \mathrm{mg} / \mathrm{m}^{2}\right)$ over $46 \mathrm{~h} \mathrm{[13].} \mathrm{Patients} \mathrm{on} \mathrm{SOX}$ or XELOX received oral S-1 (80-120 mg/body) or oral capecitabine $\left(2000 \mathrm{mg} / \mathrm{m}^{2} /\right.$ day $)$ twice daily after breakfast and dinner from days 1 to 14 and intravenous L-OHP $\left(130 \mathrm{mg} / \mathrm{m}^{2}\right)$ for $2 \mathrm{~h}$ on day 1 repeated every 3 weeks $[14,15]$. Concomitant intravenous bevacizumab $(7.5 \mathrm{mg} / \mathrm{kg})$ or cetuximab $\left(400 \mathrm{mg} / \mathrm{m}^{2}\right.$ for the first administration, $250 \mathrm{mg} / \mathrm{m}^{2}$ for the second and subsequent administrations) was administered before L-OHP. FOLFIRI (l-LV $200 \mathrm{mg} / \mathrm{m}^{2}$, day 1 ; CPT- $11150 \mathrm{mg} / \mathrm{m}^{2}$, day 1 ; 5-FU bolus $400 \mathrm{mg} /$ day, day 1; 5-FU ci $2400 \mathrm{mg} / \mathrm{m}^{2}, 48$ h; cetuximab every 2 weeks), IRIS (S-1: $80-120 \mathrm{mg} /$ body, day $1-14$; CPT-11125 $\mathrm{mg} / \mathrm{m}^{2}$, day 1 and 15 , every 4 weeks), and CPT-11 (CPT-11: $150 \mathrm{mg} / \mathrm{m}^{2}$, day 1 and 15 , every 4 weeks) were administered according to the standard protocol outlined in the Japanese guideline $[13,16]$.

Regarding these regimens, cetuximab, bevacizumab, or panitumumab were added appropriately for each patient. Other regimens for various cancers were described as follows: In brief, for gynecological cancers, TC (paclitaxel (PTX): $180 \mathrm{mg} / \mathrm{m}^{2}$, day 1 ; CDBCA: AUC5, day 1, every 3 weeks) and DC (docetaxel (DTX): $60 \mathrm{mg} / \mathrm{m}^{2}$, day 1; CBDCA: AUC5, day 1, every 3 weeks) were administered [17]. For lung cancers, PTX + CBDCA (PTX: $200 \mathrm{mg} / \mathrm{m}^{2}$, day 1, CBDCA: AUC6, day 1, every 3 weeks) and etoposide 
$(\mathrm{ETP})+\mathrm{CBDCA}\left(\mathrm{ETP}: 80 \mathrm{mg} / \mathrm{m}^{2}\right.$, day 1 ; CBDCA: AUC5, day 1 , every 3 weeks) were administered [18].

Among all chemotherapy, whether additional oral DEX (4-8 mg) on day 2-3 days of chemotherapy was administered in both the two- and three-drug groups, were decided by each doctor according to patient characteristics.

\section{Statistical analyses}

Statistical analyses were performed using the MannWhitney $U$ test and chi-square test. Continuous variables, such as the patient age, were analyzed using the Mann-Whitney $U$ test. A propensity score-matching analysis between the two groups was performed to reduce the effect of any selection bias including sex, age, primary organ, and so on. The propensity score-matching method was proposed to evaluate statistically causal effects free from confounding effects by mathematically refashioning an observational study into a randomized study $[19,20]$. Propensity scores were estimated using a logistic regression model with various covariates described above. By using these propensity scores, patients were individually matched between the two groups (a 1:1 matching). Multivariate logistic regression analyses were also performed to determine the risk factors of acute and delayed nausea. In detail, only factors showing $P<0.05$ in the univariate analysis were examined. A $p$-value $<0.05$ was considered to be statistically significant. All statistical analyses were performed using using SPSS version 22.0 (IBM Corp., Armonk, NY, USA).

\section{Results}

The patients characteristics in the two-drug and threedrug groups before and after propensity score matching are shown in Table 1. After matching, there were no significant differences in the age $(66.4 \pm 9.9$ vs. $64.7 \pm$ $9.5, p=0.49)$, or ratio of male sex (46.4 vs. $38.1, p=$ 0.24 ), between the two-drug group and three-drug group, nor in the ECOG PS. Additionally, there were no significant difference in the primary organ and type of anticancer drugs between the two groups. In addition, regarding the sequence of chemotherapy, the respective ratios for 1 st and 2 nd-3rd courses were 40.2 and $59.8 \%$ in the two-drug group and 46.4 and $53.6 \%$ in the three-drug group $(p=0.38)$.

The control rates of acute nausea in the two- and three-drug groups were 92.8 and $95.9 \%(p=0.35)$, respectively, and those of delayed nausea were 83.5 and $81.4 \%$ ( $p=0.85$ ), respectively (Fig. 2 ). The control rates of acute vomiting in the two- and three-drug groups were 95.9 and $100.0 \%(p=0.13)$, respectively, and those of delayed nausea were 96.9 and $100.0 \%(p=0.24)$, respectively.

According to each anti-cancer drug, the control rates for nausea in the two- and three-drug groups were 82.6 and $76.9 \%(p=0.49)$ for L-OHP, respectively, 78.6 and $80.6 \%(p=0.84)$ for CBDCA, respectively, 91.3 and $100.0 \%(p=0.70)$ for CPT-11, respectively, and 84.2 and $75.0 \%(p=0.30)$ for oral 5 -FU, respectively. The control rates for vomiting in the two- and three-drug groups were 95.7 and $100.0 \%(p=0.42)$ for L-OHP, respectively, 96.4 and $100.0 \%(p=0.95)$ for CBDCA, respectively, 91.3

Table 1 Patient characteristics in the two-drug (palonosetron+DEX) and three-drug (NK1RA + palonosetron+DEX) groups before and after a propensity score-matching

\begin{tabular}{|c|c|c|c|c|c|c|}
\hline & $\begin{array}{l}\text { Two-drug } \\
\text { before matching }\end{array}$ & $\begin{array}{l}\text { Three-drug } \\
\text { before matching }\end{array}$ & $p$ value & $\begin{array}{l}\text { Two-drug } \\
\text { after matching }\end{array}$ & $\begin{array}{l}\text { Three-drug } \\
\text { after matching }\end{array}$ & $p$ value \\
\hline Case number & 97 & 215 & & 97 & 97 & \\
\hline Age $($ mean $\pm S D)$ & $66.4 \pm 9.9$ & $63.2 \pm 11.2$ & 0.011 & $66.4 \pm 9.9$ & $64.7 \pm 9.5$ & 0.49 \\
\hline \multirow[t]{2}{*}{$\operatorname{Sex}(M / F), n(\%)$} & $45 / 52$ & $103 / 112$ & \multirow[t]{2}{*}{0.80} & $45 / 52$ & $37 / 60$ & \multirow[t]{2}{*}{0.24} \\
\hline & $(46.4 / 53.6)$ & $(47.9 / 52.1)$ & & $(46.4 / 53.6)$ & $(38.1 / 61.9)$ & \\
\hline \multirow[t]{2}{*}{ ECOG PSO/1,2, n (\%) } & $54 / 43$ & $96 / 119$ & \multirow[t]{2}{*}{0.07} & $54 / 43$ & $51 / 46$ & \multirow[t]{2}{*}{0.67} \\
\hline & $(55.7 / 44.3)$ & $(44.7 / 55.3)$ & & $(55.7 / 44.3)$ & $(51.5 / 48.5)$ & \\
\hline \multirow{2}{*}{$\begin{array}{l}\text { Primary organ, n (\%) Colon/Ovary+Uterus/Lung/ } \\
\text { Stomach }\end{array}$} & $56 / 16 / 14 / 11$ & $155 / 37 / 9 / 14$ & \multirow[t]{2}{*}{0.003} & $56 / 16 / 14 / 11$ & $57 / 24 / 7 / 9$ & \multirow[t]{2}{*}{0.24} \\
\hline & $\begin{array}{l}(57.7 / 16.5 / 14.4 / \\
11.3)\end{array}$ & $\begin{array}{l}(72.1 / 17.2 / 4.2 / \\
6.5)\end{array}$ & & $\begin{array}{l}(57.7 / 16.5 / 14.4 / \\
11.3)\end{array}$ & $\begin{array}{l}(58.8 / 24.7 / 7.2 / \\
9.3)\end{array}$ & \\
\hline \multirow[t]{2}{*}{ Type of anticancer drugs, n (\%) L-OHP/CBDCA/CPT-11 } & $46 / 28 / 23$ & $132 / 46 / 37$ & \multirow[t]{2}{*}{0.07} & $46 / 28 / 23$ & $52 / 31 / 14$ & \multirow[t]{2}{*}{0.26} \\
\hline & $(47.4 / 28.9 / 23.7)$ & $(61.4 / 21.4 / 17.2)$ & & $(47.4 / 28.9 / 23.7)$ & $(53.6 / 33.0 / 14.4)$ & \\
\hline \multirow{2}{*}{$\begin{array}{l}\text { Sequence of chemotherapy, n (\%) 1st course/2nd-3rd } \\
\text { courses }\end{array}$} & $39 / 58$ & $88 / 127$ & \multirow[t]{2}{*}{0.90} & $39 / 58$ & $45 / 52$ & \multirow[t]{2}{*}{0.38} \\
\hline & $(40.2 / 59.8)$ & $(40.9 / 59.1)$ & & $(40.2 / 59.8)$ & $(46.4 / 53.6)$ & \\
\hline $\begin{array}{l}\text { Additional oral DEX on day 2-3 of chemotherapy, } \\
n(\%)\end{array}$ & $9(9.3)$ & $30(14.0)$ & 0.25 & $9(9.3)$ & $12(12.4)$ & 0.49 \\
\hline
\end{tabular}




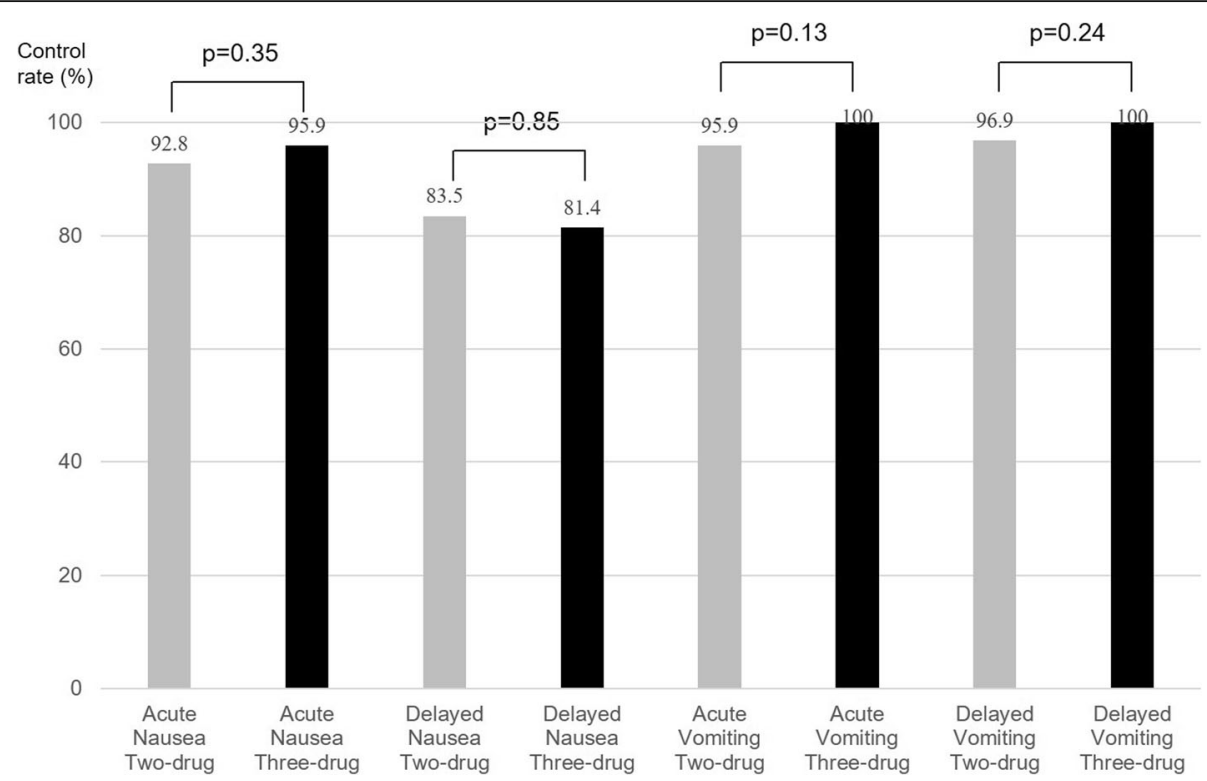

Fig. 2 The control rates for acute and delayed nausea and vomiting in the two-drug (palonosetron+DEX) and three-drug (NK1RA + palonosetron+DEX) groups after a propensity score matching

and $100.0 \%(\mathrm{p}=0.70)$ for CPT-11, respectively, and 94.7 and $100.0 \%(p=0.37)$ for oral 5-FU, respectively.

The results of an analysis of the cases with or without overall nausea and among all 312 cases administered palonosetron are shown in Table 2 . There were significant differences in the median age $(60.4 \pm 12.6$ vs. $65.2 \pm$ 10.2 years), $p<0.001)$, constipation ( $42.4 \%$ vs. $31.8 \%, p=$ $0.03)$, neuropathy $(71.2 \%$ vs. $53.6 \%, p=0.03)$, and general fatigue $(74.2 \%$ vs. $44.3 \%, \mathrm{p}<0.001)$ between the cases with and without overall nausea, respectively.

The results of univariate and multivariate analyses of the risk factors for acute nausea are shown in Table 3. The multivariate analysis showed the significant risk factors to be elevation of CRE (odds ratio [OR], 12.601; 95\% confidence interval [CI], 2.43765.157; $p=0.003)$, general fatigue (OR, 3.728; 95\%CI, $1.098-12.661, p=0.035$ ), and PS 2 (OR, 19.829; 95\% CI, 3.200-122.865; $p=0.001$ ).

The results of univariate and multivariate analyses of the risk factors for delayed nausea are shown in Table 4. The multivariate analysis showed the significant risk factors to be elevation of ALT (OR, 2.397; 95\% CI, 1.1534.984; $p=0.019)$, general fatigue $(\mathrm{OR}, 2.652 ; 95 \% \mathrm{CI}$, $1.380-5.097, \mathrm{p}=0.003)$, and PS $2(\mathrm{OR}, 5.748 ; 95 \% \mathrm{CI}$, $1.392-23.740 ; p=0.016)$.

\section{Discussion}

Previous reports on HEC regimens have shown that the control rate of 3-drug treatment using NK1RA + first-generation 5HT3RA + DEX for vomiting (51-73\%) is significantly better than those of two-drug treatments, such as first-generation 5HT3RA + DEX (42-52\%) [21-24].
However, with respect to nausea, the control rates are only $33-49 \%$ even with three-drug treatments and $24-$ $44 \%$ with two-drug treatments (not significant). However, a study (TRIPLE trial) on HEC including cisplatin $\left(>50 \mathrm{mg} / \mathrm{m}^{2}\right)$ showed that NK1RA + palonosetron+DEX controlled delayed nausea and vomiting better than NK1RA + first-generation 5HT3RA + DEX $(67.0 \%$ vs. $59.0 \%, p=0.0142$ ) [25], Another study of three-drug treatment with palonosetron for HEC including cisplatin $(>50 \mathrm{mg} / \mathrm{m} 2)$ showed no nausea rates were $61.5-$ $70.4 \%$ during 6 cycles of chemotherapy [26]. These results suggest that palonosetron might have higher efficacy against delayed nausea than first-generation 5HT3RA. A RCT of MEC regimens using L-OHP also showed that the control rates for nausea in the acute and delayed phases were better ( 93.4 and $83.2 \%$ ) in the two-drug combination (palonosetron+DEX) than those (82.7 and $70.9 \%, p<0.001, p=0.005)$ in the three-drug combination (NK1RA + first-generation 5HT3RA + DEX) [9]. Our rates (92.8 and 83.5\%) for palonosetron+DEX were also similar to these previously reported findings. Furthermore, our study failed to show the superiority of control for acute and delayed nausea with NK1RA + palonosetron+DEX (95.9 and 81.4\%, respectively) compared to these rates with palonosetron+DEX. This finding suggests that two-drug treatment (palonosetron $+\mathrm{DEX})$ is sufficient for achieving control of nausea in MEC regimens, although the control rate was not enough. This two-drug treatment is also recommended due to good compliance without a prescription for NK1RA as well as its low cost compared with three drug treatment (NK1RA + palonosetron+DEX). 
Table 2 Results of the analysis of cases with or without overall nausea among 312 cases receiving palonosetron

\begin{tabular}{|c|c|c|c|}
\hline & Cases with nausea & Cases without nausea & $p$ value \\
\hline Case number & $66(21.2 \%)$ & $246(78.8 \%)$ & \\
\hline Age, mean $\pm S D$ & $60.4 \pm 12.6$ & $65.2 \pm 10.2$ & $<0.001$ \\
\hline$\geq 75$ years, $\mathrm{n}(\%)$ & $5(7.6)$ & $42(17.1)$ & 0.05 \\
\hline$\geq 70$ years, $\mathrm{n}(\%)$ & $19(28.8)$ & $91(37.0)$ & 0.21 \\
\hline \multirow[t]{2}{*}{ Sex, n (\%) } & $28: 38$ & $120: 126$ & 0.35 \\
\hline & $(42.4: 57.6)$ & $(48.8: 51.2)$ & \\
\hline \multirow[t]{2}{*}{ PS 0:1 + 2, n (\%) } & $26: 40$ & 129:117 & 0.05 \\
\hline & $(39.4: 60.6)$ & $(52.4: 47.6)$ & \\
\hline Aprepitant, n (\%) & $50(75.8)$ & $165(67.0)$ & 0.17 \\
\hline Neut < 1000, n (\%) & $5(7.6)$ & $18(7.3)$ & 0.63 \\
\hline $\mathrm{Hb}<10$ mg/dl, n (\%) & $32(48.5)$ & $142(57.7)$ & 0.18 \\
\hline CRE $\geq 1.1 \mathrm{mg} / \mathrm{dl}, \mathrm{n}(\%)$ & $7(6,5)$ & $7(2.8)$ & 0.07 \\
\hline ALT > 2.5 ULN, n (\%) & $17(25.8)$ & $38(15.9)$ & 0.05 \\
\hline Constipation, n (\%) & $28(42.4)$ & $70(31.8)$ & 0.03 \\
\hline Diarrhea, n (\%) & $19(28.8)$ & $48(19.0)$ & 0.10 \\
\hline Oral mucositis, n (\%) & $20(30.3)$ & $57(20.8)$ & 0.23 \\
\hline Neuropathy, n (\%) & $47(71.2)$ & $139(53.6)$ & 0.03 \\
\hline General fatigue, n (\%) & $49(74.2)$ & $113(44.3)$ & $<0.001$ \\
\hline Pain NRS $\geq 1, n(\%)$ & $22(33.3)$ & $69(31.5)$ & 0.40 \\
\hline L-OHP, n (\%) & $42(63.6)$ & $136(55.3)$ & 0.22 \\
\hline СРТ-11, n (\%) & $8(12.1)$ & $52(21.1)$ & 0.09 \\
\hline CBDCA, n (\%) & $16(24.2)$ & $58(23.6)$ & 0.91 \\
\hline Oral intake of 5-FU, n (\%) & $39(59.1)$ & $116(47.2)$ & 0.08 \\
\hline
\end{tabular}

PS performance status, NEUT neutrophil, ULN upper limit of normal, NRS numerical rating score, L-OHP oxaliplatin, CPT-11 irinotecan, CBDCA carboplatin, SD standard deviation

However, a small Japanese crossover study of 35 patients receiving MEC regimens using $\mathrm{L}-\mathrm{OHP}$ and $\mathrm{CPT}-11$ showed the total control rate for severe to mild nausea to be $46 \%$ for palonosetron+DEX and $60 \%$ for NK1RA + first-generation 5HT3RA + DEX $(p=0.235)$ [27]. This result is not consistent with the result of our study. Thus, a large prospective randomized study should be performed to prove which treatments (e.g. palonosetron+DEX or NK1RA + first-generation 5HT3RA + DEX) are better for controlling nausea associated with various MEC regimens.

Regarding vomiting, a study comparing two-drug (palonosetron+DEX) and three-drug combinations (NK1RA + first-generation 5HT3RA + DEX) for an L-OHP-based regimen showed the rates of no vomiting in the acute and delayed phases to be 99.4 and $95.5 \%$, respectively, with the 2-drug combination [28]. Our rates of no vomiting in the acute and delayed phases in the two-drug group (palonosetron+DEX) were 95.9 and $96.9 \%$, respectively, which were almost the same as in that previous study. In addition, our data showed the rates of no vomiting in the acute and delayed phases in the three-drug group (NK1RA + palonosetron+DEX) to be 100.0 and $100.0 \%$, respectively. This suggests that two-drug treatment (palonosetron+DEX) was sufficient to control vomiting associated with an MEC regimen. Indeed, ASCO and MASCC/ESMO recommend palonosetron for MEC when NK1RA is not used $[4,5]$.

Even though MEC regimens include various kinds of anti-cancer drugs, anti-emetic treatments for MEC are largely decided by guidelines [4-6]. We analyzed regimens with L-OHP, CBDCA, and CPT-11, which are all defined as MEC regimens. Regarding vomiting, palonosetron controlled more than $90 \%$ of cases in patients receiving each anti-cancer drug, regardless of inclusion in the 2- or 3-drug group. However, regarding nausea, the control rates ranged widely (78.6-91.3\%) in the 2-drug group and were not markedly improved in the 3-drug group (75.0-100.0\%). Furthermore, the control rates with CBDCA and L-OHP were lower than that with CPT-11 both in both groups. Previous studies have shown the control rate of vomiting and nausea in the CBDCA regimen to be 89.5 and $60.5 \%$ in the acute and delayed phase, respectively, with a 3-drug regimen of NK1RA + palonosetron+DEX [29]. Another study of 
Table 3 Results of univariate and multivariate analyses of risk factors of acute nausea among 312 cases with palonosetron receiving MEC

\begin{tabular}{|c|c|c|c|c|c|c|c|c|c|c|c|}
\hline & \multicolumn{6}{|c|}{ Univariate } & \multicolumn{5}{|c|}{ Multivariate } \\
\hline & $n$ & OR & $95 \% \mathrm{Cl}$ & & & $P$-value & $\overline{\mathrm{OR}}$ & $95 \% \mathrm{Cl}$ & & & $P$-value \\
\hline Age $<75$ vs. $\geq 75$ years & 312 & n.c. & & & & & - & & & & \\
\hline Sex Female (vs. Male) & 312 & 1.162 & 0.510 & , & 2.647 & 0.720 & - & & & & \\
\hline Anti-cancer drug & 312 & & & & & & - & & & & \\
\hline $\mathrm{L}-\mathrm{OHP}$ & 178 & 1.000 & & ref & & & & & & & \\
\hline CPT11 & 60 & 1.676 & 0.636 & , & 4.420 & 0.296 & & & & & \\
\hline CBDCA & 74 & 0.920 & 0.316 & , & 2.679 & 0.878 & & & & & \\
\hline Oral 5-FU & 312 & & & & & & - & & & & \\
\hline Nothing & 157 & 1.000 & & ref & & & & & & & \\
\hline$S-1$ & 30 & 1.859 & 0.556 & , & 6.210 & 0.314 & & & & & \\
\hline Capecitabine & 125 & 0.938 & 0.382 & , & 2.301 & 0.888 & & & & & \\
\hline Additional oral steroid days 2 or 3 (vs. Nothing) & 312 & 1.203 & 0.531 & , & 2.726 & 0.658 & - & & & & \\
\hline NK1RA (vs. Nothing) & 312 & 1.175 & 0.474 & , & 2.913 & 0.728 & - & & & & \\
\hline Primary organ & 312 & & & & & & - & & & & \\
\hline colorectal cancer & 211 & 1.000 & & ref & & & & & & & \\
\hline gastric cancer & 25 & n.c. & & & & & & & & & \\
\hline lung cancer & 23 & 1.516 & 0.412 & , & 5.572 & 0.531 & & & & & \\
\hline gynecological cancer & 53 & 0.606 & 0.173 & , & 2.131 & 0.435 & & & & & \\
\hline $\mathrm{Hb}<10 \mathrm{mg} / \mathrm{dl}$ & 312 & 1.010 & 0.443 & , & 2.301 & 0.981 & - & & & & \\
\hline Neut $<1500 / \mu l$ & 312 & 0.528 & 0.068 & , & 4.096 & 0.541 & - & & & & \\
\hline $\mathrm{PLT}<7.5 \times 10^{4} / \mu \mathrm{l}$ & 312 & 1.078 & 0.473 & , & 2.457 & 0.858 & - & & & & \\
\hline CRE $\geq 1.1 \mathrm{mg} / \mathrm{dl}$ & 312 & 6.643 & 1.848 & , & 23.881 & 0.004 & 12.601 & 2.437 & , & 65.157 & 0.003 \\
\hline AST > 2.5 ULN & 312 & 1.576 & 0.651 & , & 3.815 & 0.313 & - & & & & \\
\hline $\mathrm{ALT}>2.5 \mathrm{ULN}$ & 312 & 1.936 & 0.767 & , & 4.890 & 0.162 & - & & & & \\
\hline Fever elevation $>38^{\circ} \mathrm{C}$ & 312 & 1.696 & 0.363 & , & 7.921 & 0.502 & - & & & & \\
\hline Constipation & 312 & 1.218 & 0.506 & , & 2.933 & 0.661 & - & & & & \\
\hline Diarrhea & 312 & 3.241 & 1.397 & , & 7.522 & 0.006 & 2.594 & 0.984 & , & 6.834 & 0.054 \\
\hline Oral mucositis & 312 & 2.189 & 0.940 & , & 5.099 & 0.069 & - & & & & \\
\hline Taste alteration & 312 & 1.895 & 0.833 & , & 4.314 & 0.128 & - & & & & \\
\hline Neuropathy & 312 & 2.916 & 1.064 & , & 7.986 & 0.037 & 1.088 & 0.346 & , & 3.423 & 0.885 \\
\hline Eruption & 312 & 3.630 & 1.470 & , & 8.965 & 0.005 & 2.012 & 0.716 & , & 5.657 & 0.185 \\
\hline General fatigue & 312 & 4.085 & 1.492 & 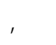 & 11.180 & 0.006 & 3.728 & 1.098 & , & 12.661 & 0.035 \\
\hline$N R S \geq 1$ & 312 & 1.406 & 0.598 & , & 3.309 & 0.435 & - & & & & \\
\hline PS & 312 & & & & & & & & & & \\
\hline 0 & 155 & 1.000 & & ref & & & 1.000 & & ref & & \\
\hline 1 & 146 & 3.435 & 1.215 & , & 9.708 & 0.020 & 2.568 & 0.820 & , & 8.043 & 0.105 \\
\hline 2 & 11 & 25.000 & 5.668 &, & 110.271 & 0.000 & 19.829 & 3.200 & , & 122.865 & 0.001 \\
\hline
\end{tabular}

MEC moderately emetogenic chemotherapy, L-OHP oxaliplatin, CPT-11 irinotecan, CBDCA carboplatin, Hb hemoglobin, Neut neutrophil, $P L T$ platelet, CRE creatine, ULN upper limit of normal, NRS numerical rating scale, PS performance status, OR odds ratio, CI confidence interval

MEC regimens using L-OHP and CPT-11 showed the overall control rate to be $69.1 \%$ and $66.7 \%$ with a 2 -drug regimen of palonosetron+DEX [30]. Thus, physicians must be alert for nausea in patients receiving regimens of CBDCA and L-OHP. As we showed in the present study, it didn't improve even in three drug treatment including NK1RA. Thus, additional anti-emetic drugs, such as 5HT2 blockers, gastrointestinal motility activator such as metoclopramide, and olanzapine should be considered [4-7,31]. These drugs are 
Table 4 Results of univariate and multivariate analyses of risk factors of delayed nausea among 312 cases with palonosetron receiving MEC

\begin{tabular}{|c|c|c|c|c|c|c|c|c|c|c|c|}
\hline \multirow{3}{*}{$\overline{\text { Age }<75 \text { vs. } \geq 75 \text { years }}$} & \multicolumn{6}{|c|}{ Univariate } & \multicolumn{5}{|c|}{ Multivariate } \\
\hline & \multirow{2}{*}{$\begin{array}{l}n \\
312\end{array}$} & \multirow{2}{*}{$\begin{array}{l}\text { OR } \\
0.444\end{array}$} & \multicolumn{3}{|l|}{$95 \% \mathrm{Cl}$} & \multirow{2}{*}{$\frac{P \text {-value }}{0.102}$} & \multirow{2}{*}{$\begin{array}{l}\mathrm{OR} \\
-\end{array}$} & \multicolumn{2}{|l|}{$95 \% \mathrm{Cl}$} & & \multirow[t]{2}{*}{$P$-value } \\
\hline & & & 0.168 & , & 1.176 & & & & & & \\
\hline Sex Female (vs. Male) & 312 & 1.273 & 0.724 & , & 2.239 & 0.402 & - & & & & \\
\hline Anti-cancer drug & 312 & & & & & & & & & & \\
\hline L-OHP & 178 & 1.000 & & ref & & & 1.000 & & ref & & \\
\hline CPT11 & 60 & 0.396 & 0.159 & , & 0.989 & 0.047 & 0.505 & 0.137 & , & 1.860 & 0.304 \\
\hline CBDCA & 74 & 0.983 & 0.509 & , & 1.898 & 0.960 & 1.769 & 0.533 & , & 5.870 & 0.351 \\
\hline Oral 5-FU & 312 & & & & & & & & & & \\
\hline Nothing & 157 & 1.000 & & ref & & & 1.000 & & ref & & \\
\hline S-1 & 30 & 0.812 & 0.261 & , & 2.530 & 0.720 & 0.671 & 0.144 & , & 3.124 & 0.611 \\
\hline Capecitabine & 125 & 1.817 & 1.011 & , & 3.266 & 0.046 & 2.111 & 0.690 & , & 6.458 & 0.190 \\
\hline Additional oral steroid days 2 or 3 (vs. Nothing) & 312 & 0.654 & 0.370 & , & 1.156 & 0.144 & - & & & & \\
\hline NK1RA (vs. Nothing) & 312 & 1.340 & 0.715 & , & 2.513 & 0.362 & - & & & & \\
\hline Primary organ & 312 & & & & & & - & & & & \\
\hline colorectal cancer & 211 & 1.000 & & ref & & & & & & & \\
\hline gastric cancer & 25 & n.c. & & & & & & & & & \\
\hline lung cancer & 23 & 1.054 & 0.371 & , & 2.998 & 0.921 & & & & & \\
\hline gynecological cancer & 53 & 1.111 & 0.539 & , & 2.291 & 0.776 & & & & & \\
\hline $\mathrm{Hb}<10 \mathrm{mg} / \mathrm{dl}$ & 312 & 0.719 & 0.410 & , & 1.260 & 0.249 & - & & & & \\
\hline Neut $<1500 / \mu l$ & 312 & 0.632 & 0.181 & , & 2.207 & 0.472 & - & & & & \\
\hline $\mathrm{PLT}<7.5 \times 10^{4} / \mu \mathrm{l}$ & 312 & 1.535 & 0.875 & , & 2.691 & 0.135 & - & & & & \\
\hline CRE $\geq 1.1 \mathrm{mg} / \mathrm{dl}$ & 312 & 3.112 & 0.953 & , & 10.167 & 0.060 & - & & & & \\
\hline AST > 2.5 ULN & 312 & 1.780 & 0.964 & , & 3.287 & 0.066 & - & & & & \\
\hline $\mathrm{ALT}>2.5 \mathrm{ULN}$ & 312 & 2.166 & 1.122 & , & 4.180 & 0.021 & 2.397 & 1.153 & , & 4.984 & 0.019 \\
\hline Fever elevation $>38^{\circ} \mathrm{C}$ & 312 & 0.574 & 0.127 & , & 2.595 & 0.471 & - & & & & \\
\hline Constipation & 312 & 0.884 & 0.470 & , & 1.664 & 0.702 & - & & & & \\
\hline Diarrhea & 312 & 1.394 & 0.729 & , & 2.666 & 0.315 & - & & & & \\
\hline Oral mucositis & 312 & 1.230 & 0.655 & , & 2.310 & 0.520 & - & & & & \\
\hline Taste alteration & 312 & 1.225 & 0.685 & , & 2.190 & 0.493 & - & & & & \\
\hline Neuropathy & 312 & 1.804 & 0.986 & , & 3.302 & 0.056 & - & & & & \\
\hline Eruption & 312 & 1.534 & 0.875 & , & 2.690 & 0.135 & - & & & & \\
\hline General fatigue & 312 & 3.221 & 1.729 & , & 6.000 & 0.000 & 2.652 & 1.380 & , & 5.097 & 0.003 \\
\hline NRS $\geq 1$ & 312 & 1.125 & 0.613 & , & 2.064 & 0.704 & - & & & & \\
\hline PS & 312 & & & & & & & & & & \\
\hline 0 & 155 & 1.000 & & ref & & & 1.000 & & ref & & \\
\hline 1 & 146 & 1.532 & 0.853 & , & 2.752 & 0.153 & 1.360 & 0.723 & , & 2.558 & 0.340 \\
\hline 2 & 11 & 4.549 & 1.285 & , & 16.101 & 0.019 & 5.748 & 1.392 & , & 23.740 & 0.016 \\
\hline
\end{tabular}

MEC moderately emetogenic chemotherapy, L-OHP oxaliplatin, CPT-11 irinotecan, CBDCA carboplatin, Hb hemoglobin, Neut neutrophil, PLT platelet, CRE creatine, ULN upper limit of normal, NRS numerical rating scale, $P S$ performance status, $O R$ odds ratio, Cl confidence interval

more economical than NK1RA. We also suggest that MEC regimens be divided into subgroups based on their rates of emesis to ensure better supportive care.

Risk factors typically associated with CINV include female gender, a younger age, a poor PS, no drinking of alcohol, and no smoking [32-39]. However, most of these risk factors were assessed concerning their association with vomiting and severe to moderate nausea. In the present study, we clarified the risk factors of all grades (severe to mild) of acute and delayed nausea. 
Elevation of CRE, general fatigue, and PS 2 were extracted as risk factors for acute nausea. In addition, elevation of ALT, general fatigue, and PS 2 were extracted as risk factors for delayed nausea. For patients with these risk factors, additional anti-emetic drugs should be considered.

To our knowledge, this is the first report to describe elevation of CRE and ALT as risk factors for CINV. We should therefore pay close attention to patients with those factors. In such patients, the addition of antiemetic agents, such as $5 \mathrm{H} 2$ blockers and olanzapine, to palonosetron+DEX may be considered [4-7]. We further suggest that additional NK1RA is not necessary for controlling nausea in patients receiving palonosetron+DEX, as there were no significant differences in the control rates for nausea between NK1RA1 + palonosetron+DEX and palonosetron+DEX.

\section{Study limitations}

This study was a retrospective review of patient medical records. Two- and three-drug treatment were decided by each doctor according to each patient's characteristics. Thus, there was a possibility of selection bias concerning inclusion in the two- and three-drug groups though we performed a propensity score matching.

\section{Conclusions}

The control rates of nausea with NK1RA + palonosetron+DEX in MEC using L-OHP, CPT-11, and CBDCA were not sufficient, especially for delayed nausea. In addition, the rates were not superior to those with palonosetron+DEX. Elevation of ALT, general fatigue, and PS 2 were considered risk factors for delayed nausea. We should therefore pay particularly close attention to patients with these risk factors.

\section{Abbreviations \\ 5-HT3RA: 5-hydroxytryptamine-3 receptor antagonist; 5-FU: 5-fluorouracil; ALT: Aspartate aminotransferase; ASCO: The American Society of Clinical Oncology; AST: Alanine aminotransferase; CBDCA: Carboplatin; Cl: Confidence interval; CINV: Chemotherapy-induced nausea and vomiting; CPT-11: Irinotecan; CRE: Creatine; DEX: Dexamethasone; DTX: Docetaxel; ECOG: Eastern Cooperative Oncology Group; ETP: Etoposide; Hb: Hemoglobin; HEC: High emetogenic chemotherapy; L-OHP: Oxaliplatin; LV: Leucovorin; MASCC: Multinational Association of Supportive Care in Cancer; MEC: Moderate emetogenic chemotherapy; NCCN: National Comprehensive Cancer Network; NCl- CTC: National Cancer Institute - Common Toxicity Criteria; NEUT: Neutrophil value; NK1RA: A neurokinin 1 receptor antagonist; NRS: Numerical rating score; OR: Odds ratio; PLT: Platelet; PS: Performance status; PTX: Paclitaxel}

\section{Acknowledgements}

We thank Norihiko Ihara, Yuki Nakajima, Yuko Kanbayashi, Rumi Kawano, Mayumi Hirao, Kiyo Ochi, and all other staff at the Outpatient Oncology Unit of Kyoto Prefectural University of Medicine Hospital for their help with this study.

\section{Funding}

There was no funding in this study.

\section{Availability of data and materials}

The patient data used to support the findings of this study are available from the corresponding author upon request. However, some of them are restricted by the institutional review board in the Kyoto Prefectural University of Medicine.

\section{Authors' contributions}

In keeping with the latest guidelines of the International Committee of Medical Journal Editors, each author's contribution to the paper is to be quantified. All authors (NY, TT, MN, KI, TO, TI, EO, KT, HK, MK, YI) read and approved the final version of the manuscript.

\section{Ethics approval and consent to participate}

This study was approved by the ethics committee of Kyoto Prefectural University of Medicine and was carried out in accordance with the World Medical Association Helsinki Declaration (adopted in 1964 and amended in 1975, 1983, 1989, 1996, 2000, 2002, 2004, and 2008). This manuscript has not been published or submitted for publication elsewhere. All authors have participated in this manuscript.

Consent for publication

Not applicable.

Competing interests

All authors declare that they have no competing interests.

\section{Publisher's Note}

Springer Nature remains neutral with regard to jurisdictional claims in published maps and institutional affiliations.

\section{Author details}

1Department of Molecular Gastroenterology and Hepatology, Graduate School of Medical Science, Kyoto Prefectural University of Medicine, 465 Kajii-cho, Kawaramachi-Hirokoji, Kamigyo-ku, Kyoto 602-8566, Japan. ${ }^{2}$ Outpatient Cancer Chemotherapy Center, Kyoto Prefectural University of Medicine Hospital, Kyoto, Japan. ${ }^{3}$ Division of Endocrinological and Breast Surgery, Kyoto Prefectural University of Medicine, Kyoto, Japan. ${ }^{4}$ Division of Digestive Surgery, Graduate School of Medical Science, Kyoto Prefectural University of Medicine, Kyoto, Japan. ${ }^{5}$ Department of Pulmonary Medicine, Kyoto Prefectural University of Medicine, Kyoto, Japan. ${ }^{6}$ Department of Obstetrics and Gynecology, Kyoto Prefectural University of Medicine, Kyoto, Japan. ${ }^{7}$ Department of Urology, Graduate School of Medicine, Kyoto Prefectural University of Medicine, Kyoto, Japan.

Received: 29 August 2018 Accepted: 6 December 2018

Published online: 14 January 2019

References

1. Sun CC, Bodurka DC, Weaver CB, et al. Rankings and symptom assessments of side effects from chemotherapy: insights from experienced patients with ovarian cancer. Support Care Cancer. 2005;13:219-27.

2. Bloechl-Daum B, Deuson RR, Mavros $P$, et al. Delayed nausea and vomiting continue to reduce patients' quality of life after highly and moderately emetogenic chemotherapy despite antiemetic treatment. J Clin Oncol. 2006;24:4472-8

3. Lorusso V, Spedicato A, Petrucelli $L$, et al. Single dose of palonosetron plus dexamethasone to control nausea, vomiting and to warrant an adequate food intake in patients treated with highly emetogenic chemotherapy (HEC). Preliminary results Support Care Cancer. 2009;17:1469-73.

4. Gralla RJ, Roila F, Tonato M, et al. Title of subordinate document. In: MASCC/ ESMO antiemetic guideline. In: Multinational Association of Supportive Care in Cancer; 2013. http://www.mascc.org/assets/Guidelines-Tools/mascc_ guidlines_english_2014.pdf. Accessed Dec 2014

5. Basch E, Prestrud AA, Hesketh PJ, et al. Antiemetics: American Society of Clinical Oncology clinical practice guideline update. J Clin Oncol. 2011; 29:4189-98

6. Ettinger DS, Berger MJ, Armstrong DK, et al. Title of subordinate document. In: NCCN version 2. In: Antiemesis National Comprehensive Cancer Network; 2014. http://www.nccn.org/professionals/physician_gls/pdf/antiemesis.pdf. Accessed Mar 2015 
7. Japan Society of Clinical Oncology. In: for Antiemesis, editor. JSCO Clinical Practice Guideline. Tokyo, Japan: Kanehara \& Co., Ltd; 2015.

8. Chawa SP, Grunberg SM, Gralla RJ, et al. Establishing the dose of the oral NK1 antagonist aprepitant for the prevention of chemotherapy-induced nausea and vomiting. Cancer. 2013;97:2290-300.

9. Nishimura J, Satoh T, Fukunaga M, et al. Combination antiemetic therapy with aprepitant/fosaprepitant in patients with colorectal cancer receiving oxaliplatin-based chemotherapy (SENRI trial): a multicentre, randomised, controlled phase 3 trial. Eur J Cancer. 2015;51:1274-82.

10. Aapro MS. Palonosetron as an anti-emetic and anti-nausea agent in oncology. Ther Clin Risk Manag. 2007;3:1009-20.

11. Oken MM, Creech RH, Tormey DC, et al. Toxicity and response criteria of the eastern cooperative oncology group. Am J Oncol. 1982;5:649-55.

12. National Cancer Institute. Common Terminology Criteria for Adverse Events (CTCAE) v4.0. 2009. http://evs.nci.nih.gov/ftp1/CTCAE/About.html.

13. Van Cutsem E, Rivera F, Berry S, et al. Safety and efficacy of first-line bevacizumab with FOLFOX, XELOX, FOLFIRI and fluoropyrimidines in metastatic colorectal cancer: the BEAT study. Ann Oncol. 2009;20:1.

14. Cassidy J, Clarke S, Díaz-Rubio E, et al. Randomized phase III study of capecitabine plus oxaliplatin compared with fluorouracil/folinic acid plus oxaliplatin as first-line therapy for metastatic colorectal cancer. J Clin Oncol. 2008;26:2006-12.

15. Yamada Y, Tahara M, Miya T, et al. Phase I/II study of oxaliplatin with oral S1 as first-line therapy for patients with metastatic colorectal cancer. $\mathrm{Br} J$ Cancer. 2008;98:1034-8.

16. Muro K, Boku N, Shimada Y, et al. Irinotecan plus S-1 (IRIS) versus fluorouracil and folinic acid plus irinotecan (FOLFIRI) as second-line chemotherapy for metastatic colorectal cancer: a randomised phase 2/3 non-inferiority study (FIRIS study). Lancet Oncol. 2010;11:853-60.

17. Komiyama S, Katabuchi H, Mikami M, et al. Japan Society of Gynecologic Oncology guidelines 2015 for the treatment of ovarian cancer including primary peritoneal cancer and fallopian tube cancer. Int J Clin Oncol. 2016; 21:435-46.

18. Wang F, Mishina S, Takai S, et al. Systemic treatment patterns with advanced or recurrent non-small cell lung Cancer in Japan: a retrospective hospital administrative database study. Clin Ther. 2017; 39:1146-60

19. Rubin DB. Estimating causal effects from large data sets using propensity scores. Ann Intern Med. 1997;127:757-63.

20. Katayama M, Inui N, Tanaka K, et al. Prophylactic aprepitant is better than salvage for carboplatin-based chemotherapy: a propensity score-matched analysis. Med Oncol. 2018;35:139.

21. Hesketh PJ, Grunberg SM, Gralla RJ, et al. The oral neurokinin-1 antagonist aprepitant for the prevention of chemotherapy-induced nausea and vomiting: a multinational, randomized, double-blind, placebo-controlled trial in patients receiving high-dose cisplatin--the Aprepitant protocol 052 study group. J Clin Oncol. 2003;21:4112-9.

22. Poli-Bigelli S, Rodrigues-Pereira J, Carides AD, et al. Addition of the neurokinin 1 receptor antagonist aprepitant to standard antiemetic therapy improves control of chemotherapy-induced nausea and vomiting. Results from a randomized, double-blind, placebo-controlled trial in Latin America. Cancer. 2003;97:3090-8.

23. Warr DG, Hesketh PJ, Gralla RJ, et al. Efficacy and tolerability of aprepitant for the prevention of chemotherapy-induced nausea and vomiting in patients with breast cancer after moderately emetogenic chemotherapy. J Clin Oncol. 2005;23:2822-30.

24. Takahashi T, Hoshi E, Takagi M, et al. Multicenter, phase II, placebocontrolled, double-blind, randomized study of aprepitant in Japanese patients receiving high-dose cisplatin. Cancer Sci. 2010;101:2455-61.

25. Suzuki K, Yamanaka T, Hashimoto H, et al. Randomized, double-blind, phase III trial of palonosetron versus granisetron in the triplet regimen for preventing chemotherapy-induced nausea and vomiting after highly emetogenic chemotherapy: TRIPLE study. Ann Oncol. 2016;27:1601-6.

26. Longo F, Mansueto G, Lapadula V, et al. Combination of aprepitant, palonosetron and dexamethasone as antiemetic prophylaxis in lung cancer patients receiving multiple cycles of cisplatin-based chemotherapy. Int J Clin Pract. 2012;66:753-7.

27. Toda H, Kawazoe H, Yano A, et al. Antiemetic effectiveness and cost-saving of Aprepitant plus Granisetron is superior to Palonosetron in gastrointestinal Cancer patients who received moderately Emetogenic chemotherapy. J Cancer. 2017;8:1371-7.
28. Kitayama H, Tsuji Y, Sugiyama J, et al. Efficacy of palonosetron and 1-day dexamethasone in moderately emetogenic chemotherapy compared with fosaprepitant, granisetron, and dexamethasone: a prospective randomized crossover study. Int J Clin Oncol. 2015;20:1051-6.

29. Fujiwara S, Terai Y, Tsunetoh S, et al. Palonosetron versus granisetron in combination with aprepitant for the prevention of chemotherapy-induced nausea and vomiting in patients with gynecologic cancer. J Gynecol Oncol. 2015;26:311-9.

30. Komatsu Y, Okita K, Yki S, et al. Open-label, randomized, comparative, phase III study on effects of reducing steroid use in combination with Palonosetron. Cancer Sci. 2015;106:891-5.

31. Mehra N, Ganesan P, Ganesan TS, et al. Effectiveness of olanzapine in patients who fail therapy with aprepitant while receiving highly emetogenic chemotherapy. Med Oncol. 2017;35:12.

32. Sekine I, Segawa Y, Kubota K, et al. Risk factors of chemotherapy-induced nausea and vomiting: index for personalized antiemetic prophylaxis. Cancer Sci. 2013;104:711-7.

33. Osoba D, Zee B, Pater J, Warr D, et al. Determinants of postchemotherapy nausea and vomiting in patients with cancer. Quality of life and symptom control committees of the National Cancer Institute of Canada clinical trials group. J Clin Oncol. 1997;15:116-23.

34. Hesketh $P$, Navari R, Grote T, et al. Double-blind, randomized comparison of the antiemetic efficacy of intravenous dolasetron mesylate and intravenous ondansetron in the prevention of acute cisplatin-induced emesis in patients with cancer. Dolasetron comparative chemotherapy-induced Emesis prevention group. J Clin Oncol. 1996;14:2242-9.

35. Warr D. Prognostic factors for chemotherapy induced nausea and vomiting. Eur J Pharmacol. 2014;5(722):192-6.

36. Pollera CF, Giannarelli D, et al. Prognostic factors influencing cisplatininduced emesis. Definition and validation of a predictive logistic model. Cancer. 1989;64:1117-22.

37. Tsuji Y, Baba H, Takeda K, et al. Chemotherapy-induced nausea and vomiting (CINV) in 190 colorectal cancer patients: a prospective registration study by the CINV study group of Japan. Expert Opin Pharmacother. 2017;18:753-8.

38. Tsuji D, Suzuki K, Kawasaki Y, et al. Risk factors associated with chemotherapy-induced nausea and vomiting in the triplet antiemetic regimen including palonosetron or granisetron for cisplatin-based chemotherapy: analysis of a randomized, double-blind controlled trial. Support Care Cancer. 2018. https://doi.org/10.1007/s00520-018-4403-y. Epub ahead of print.

39. Puri S, Hyland KA, Weiss KC, et al. Prediction of chemotherapy-induced nausea and vomiting from patient-reported and genetic risk factors. Support Care Cancer. 2018;26:2911-8.

Ready to submit your research? Choose BMC and benefit from

- fast, convenient online submission

- thorough peer review by experienced researchers in your field

- rapid publication on acceptance

- support for research data, including large and complex data types

- gold Open Access which fosters wider collaboration and increased citations

- maximum visibility for your research: over $100 \mathrm{M}$ website views per year

At BMC, research is always in progress.

Learn more biomedcentral.com/submissions 